\title{
High-power test and thermal characteristics of a new radio-frequency quadrupole cavity for the Japan Proton Accelerator Research Complex linac
}

\author{
Yasuhiro Kondo, ${ }^{*}$ Takatoshi Morishita, Kazuo Hasegawa, Etsuji Chishiro, Koichiro Hirano, \\ Toshihiko Hori, Hidetomo Oguri, Fumiaki Sato, and Shinichi Shinozaki \\ Japan Atomic Energy Agency (JAEA), Tokai, Naka, Ibaraki, 319-1195, Japan
}

Takashi Sugimura, Hiroshi Kawamata, Fujio Naito, Yuji Fukui, Kenta Futatsukawa, and Kesao Nanmo

High Energy Accelerator Research Organization (KEK), Tsukuba, Ibaraki, 305-0801, Japan

(Received 21 January 2013; published 9 April 2013)

\begin{abstract}
We performed a high-power test of a new radio-frequency quadrupole (RFQ II) for the J-PARC linac. RFQ II was developed as a spare RFQ because the operating J-PARC RFQ has suffered from a sparking problem. First, the conditioning of RFQ II was carried out; after $50 \mathrm{~h}$ of conditioning, RFQ II became very stable with a nominal power and duty of $330 \mathrm{~kW}$ and $3 \%$, respectively. Next the thermal properties were measured because the resonant frequency of RFQ II is tuned by changing the temperature of the cooling water. The frequency response was measured and compared to finite-element method simulation results, confirming that the simple two-dimensional model reproduces the experimental data well. The differences in the field distribution with changes in the rf loading and the cooling-water temperature were also measured, and no serious field distortion was observed. Therefore, we conclude that RFQ II can perform well as a high-power rf cavity.
\end{abstract}

DOI: 10.1103/PhysRevSTAB.16.040102

PACS numbers: 29.20.Ej

\section{INTRODUCTION}

The Japan Proton Accelerator Research Complex (J-PARC) is a multipurpose facility for particle physics, nuclear physics, materials and life science, and so on. The J-PARC accelerator consists of a 400-MeV linac, a $3-\mathrm{GeV}$ rapid-cycling synchrotron [1], and a 50-GeV main ring [2]. The original design energy and peak beam current of the linac are $400 \mathrm{MeV}$ and $50 \mathrm{~mA}$, respectively, although, in the initial phase, operation began with an energy of $181 \mathrm{MeV}$, omitting the annular-ring coupling structures [3]. A four-vane-type radio-frequency quadrupole (RFQ) built for the Japan hadron facility project is used for the initial phase linac; the design peak beam current of this $\mathrm{RFQ}$ is $30 \mathrm{~mA}$ [4]. Because a sparking problem occurred in this RFQ [5], another RFQ was newly fabricated [6] as a spare for the operating RFQ. We call this spare RFQ II, whereas the operating one is called RFQ I [7]. Table I lists the design parameters of RFQ II.

The beam dynamics design of RFQ II is the same as that of RFQ I; however, in designing the RFQ II cavity, various points that would cause discharge problems in RFQ I were greatly improved as follows.

(i) The rf structure of RFQ I is installed in a large vacuum vessel. The surface area of this type of system is

\footnotetext{
*yasuhiro.kondo@j-parc.jp
}

Published by the American Physical Society under the terms of the Creative Commons Attribution 3.0 License. Further distribution of this work must maintain attribution to the author(s) and the published article's title, journal citation, and DOI. very large; thus, it is difficult to obtain good vacuum quality. Therefore, a vacuum-tight cavity structure is adopted for RFQ II. To this end, we adopted brazing for the assembly method [6]. In the final stage of brazing, the temperature of the cavity surface reaches more than $800^{\circ} \mathrm{C}$. At this temperature, the damaged layer by machining is recrystallized, decreasing the defects that make the electronic structure of the surface unstable. Additionally, attached substances are baked out during the brazing process; thus, the finished surface is very clean. These features also contribute to improving the resistance to discharging.

TABLE I. Design parameters of J-PARC RFQ II.

\begin{tabular}{lc}
\hline \hline Beam species & $\mathrm{H}^{-}$ \\
Resonant frequency & $324 \mathrm{MHz}$ \\
Injection energy & $50 \mathrm{keV}$ \\
Extraction energy & $3 \mathrm{MeV}$ \\
Peak beam current & $30 \mathrm{~mA}$ \\
Vane length & $3172 \mathrm{~mm}$ \\
Average bore radius $\left(r_{0}\right)$ & $3.69 \mathrm{~mm}$ \\
$\rho_{t} / r_{0}$ ratio $^{\text {a }}$ & $0.89\left(\rho_{t}=3.28 \mathrm{~mm}\right)$ \\
Intervane voltage & $82.9 \mathrm{kV}$ \\
Maximum surface field & $31.6 \mathrm{MV} / \mathrm{m}(1.77 \mathrm{Kilpatrick})$ \\
Nominal peak power & $330 \mathrm{~kW}$ \\
Repetition rate & $50 \mathrm{~Hz}$ \\
rf pulse length & $600 \mu \mathrm{s}$ \\
Duty & $3 \%$ \\
\hline
\end{tabular}

${ }^{\mathrm{a}} \rho_{t}$ : transverse radius of the vane tip.

${ }^{\mathrm{b}}$ The requirement for RFQ II is $25 \mathrm{~Hz}$ but RFQ II is designed to withstand $50 \mathrm{~Hz}$. 
(ii) The material of the RFQ I cavity is $0.2 \%$ silverdoped oxygen-free copper (OFC) because it is easier to machine. In contrast, for RFQ II, pure OFC was used to prioritize resistance to discharging over machinability. Moreover, RFQ I tends to start discharging after a certain operating time; therefore, hot isostatic pressing (HIP) [9] is applied to the material of the RFQ II cavity to prevent the vane tip from absorbing gases during operation.

(iii) Specially ordered concave-formed cutters were used to machine the vane tips of RFQ I; however, the machining friction of the formed cutters is rather large, so the surface machined with them tends to be rough. Therefore, commercially available ball-nose cutters were used for machining of the RFQ II vane tips [10]. In addition, to remove the fine edges formed by ball-nose cutters, chemical polishing [11] was adopted.

(iv) RFQ I was equipped with $\pi$-mode stabilizing loops (PISLs) [12] to prevent dipole mode mixing. However, we decided not to use the PISLs and adopted a four-rod-type dipole stabilizer (DSR) [13] for RFQ II [14], because the PISLs are suspected of being a potential source of discharging and multipacting. The electric-field strength between the PISL and its penetration is almost the same as that of the intervane field, and the complicated structure of the PISL would be a source of gas emission and multipacting.

(v) The final point is that the mechanical autotuners were discarded to improve the mechanical reliability. Instead, the resonant frequency is fine-tuned during the operation by adjusting the temperature of the cooling water, as in other RFQs $[15,16]$.

In this paper, the high-power test results for J-PARC RFQ II, which is improved compared to RFQ I as noted above, are described. In particular, related to the last point listed above, we performed experiments on frequency tuning by cooling-water-temperature control, and the results are presented. First, in Sec. II, the details of the experimental apparatus are presented, and in Sec. III, the conditioning results are shown. Then, the model used to simulate the thermal properties is described in Sec. IV, and the results of experiments on the thermal characteristics and a comparison to the simulations results are discussed in Sec. V. Finally, in Sec. VI, we summarize the paper.

\section{EXPERIMENTAL APPARATUS}

Figures 1 and 2 show a schematic drawing and a crosssectional view of J-PARC RFQ II, respectively. In Fig. 2, the upper right quadrant is denoted as Q1, the upper left is $\mathrm{Q} 2$, the lower left is Q3, and the lower right is Q4; right and left are defined as viewed from upstream.

RFQ II consists of three longitudinally segmented unit cavities, and the vane lengths of the units are 1057.2, 1053.6, and $1061.3 \mathrm{~mm}$, respectively. One unit cavity consists of upper and lower major vanes and left and right

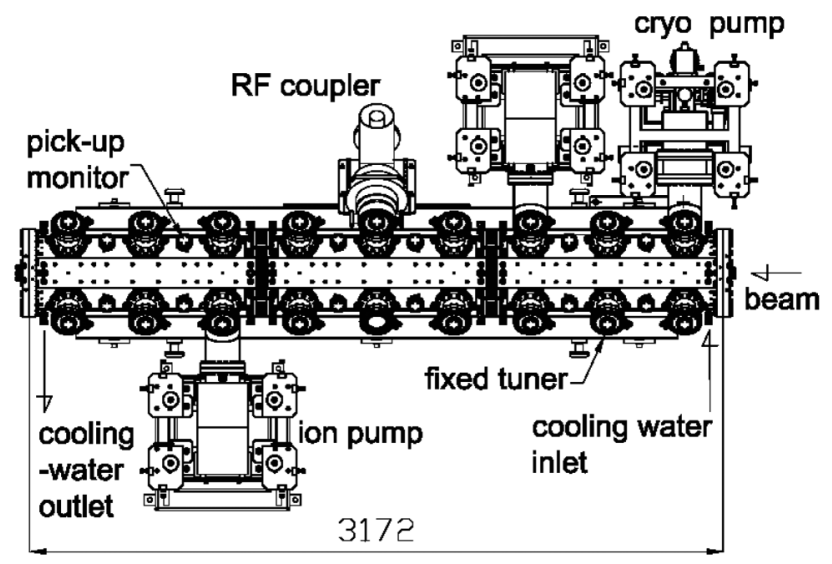

FIG. 1. Schematic of RFQ II (top view).

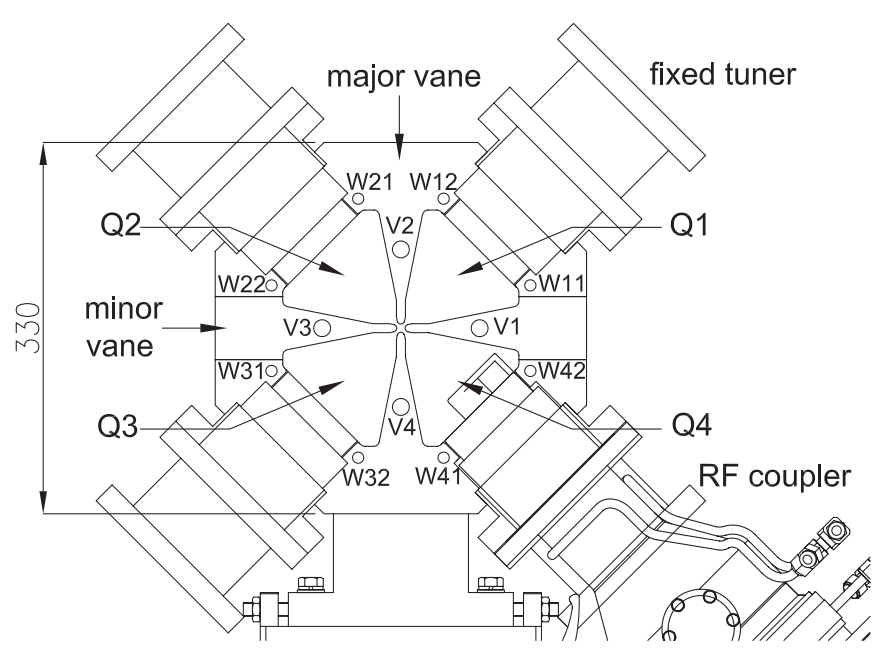

FIG. 2. Cross-sectional view (viewed from upstream) of RFQ II.

minor vanes. The major and minor vanes were joined by vacuum brazing. The material of the cavity is OFC class 1 [17], and HIP treatment was applied to reduce the voids between the crystal grains, as mentioned in Sec. I.

The resonant-frequency error and field distortion due to fabrication error are corrected using fixed tuners. The fixed slug tuner is slitted and also works as a vacuum port. Q4 has eight fixed tuners, and the other quadrants have nine fixed tuners each; thus, the total number of fixed tuners is 35 .

Vacuum pumping is possible from all ports except the radio-frequency (rf) coupler port, but in the present experiments, a $1700 \mathrm{~L} / \mathrm{s}$ (for $\mathrm{N}_{2}$ ) cryopump was attached to the first port (from upstream) of Q4, and two $400 \mathrm{~L} / \mathrm{s}$ ion pumps were attached to the eighth port of Q3 and the third port of Q4, respectively. The pressure was measured with a Bayard-Alpert (BA) gauge attached to the most downstream port of Q4.

In the center port of Q4, a loop-type rf coupler was inserted. The rf power was generated by a 324-MHz klystron (Toshiba E3740A [18]). The rf power was transmitted 
via WR2300 rectangular waveguides to the vicinity of RFQ II, transformed to WX203D coaxial waveguides, reduced to $152 \mathrm{D}$, and finally reduced to $77 \mathrm{D}$ by the rf coupler.

The field distribution during operation can be measured with loop-type pickup monitors. Six pickups are installed in each quadrant; thus, the total number of pickups is 24 .

To adjust the resonant frequency by controlling the cooling-water temperature, RFQ II is equipped with two types of cooling-water channels. Four channels are used to cool the vanes, and the other eight channels are used to cool the cavity walls. In Fig. 2, V1, V2, .. are vane cooling channels, and W11, W12, ... are wall cooling channels. The resonant frequency of an RFQ cavity $f$ is represented as $f=\frac{1}{2 \pi \sqrt{L C}}$, where $L$ is the inductance of a current circulating among the cavity wall and vanes, and $C$ is the capacitance between the vane tips. By denoting the crosssectional area of a quadrant as $A$ and the intervane gap length as $d$, the relations $L \propto A$ and $C \propto d^{-1}$ can be derived. Therefore, by adjusting the wall-water temperature $T \mathrm{w}$ and vane-water temperature $T \mathrm{v}, L$ and $C$ can be controlled individually. Methods of adjusting either $T \mathrm{v}$ and $T \mathrm{w}$ while keeping the other temperature constant are available, but at this time, $T \mathrm{v}$ was adjusted because the frequency response is faster than that obtained by changing $T \mathrm{w}$. The diameter of the vane channels is $15 \mathrm{~mm}$ and that of the wall channels is $10 \mathrm{~mm}$. The water flows in each channel are parallel from the low-energy end to the highenergy end, and the channels of three unit cavities are serially connected. The water channels of the three fixed tuners are connected serially, and the end plates and rf coupler each have a water channel. The water temperatures at the exits of all the channels are measured with resistance thermometers (PT100), and the flow rates are measured with float-type flow meters.

To verify the frequency tuning using the cooling-water temperature, a compact water-temperature-control unit for the RFQ high-power test was developed. The water from this unit is used for the vane channel, and the water supplied from the utility of the J-PARC linac at a constant temperature is used for the wall channel. Figures 3 and 4 show a schematic diagram and a photograph of this unit, respectively.

The $27^{\circ} \mathrm{C}$ water from the utility is cooled using a $25-\mathrm{kW}$ heat exchanger. The flow rate into this unit is measured with a flow indicator, FI1. The temperature at the exit of the heat exchanger (temperature of supply water to the vane channel $T$ vs) is measured with a temperature-indicating controller, TIC1. This temperature is compared with a target temperature, and heat removal is controlled by driving a three-way motor-operated valve, MV6, at the

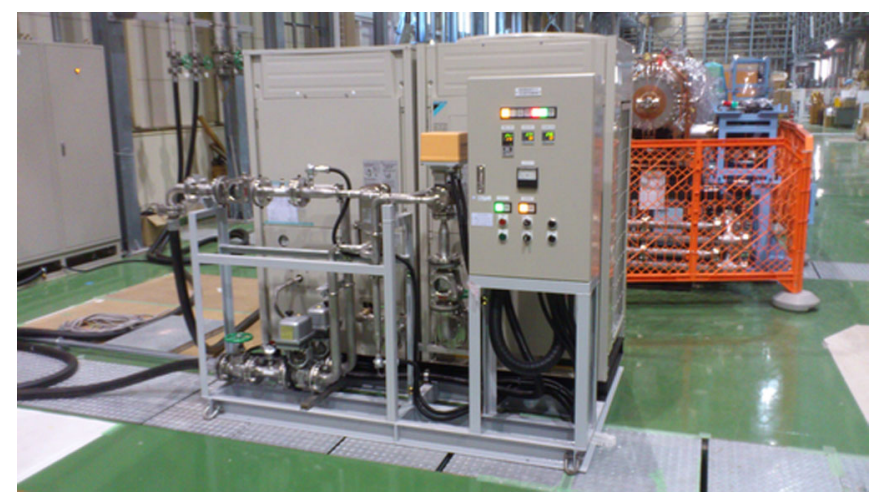

FIG. 4. Photograph of the water-temperature-control unit.

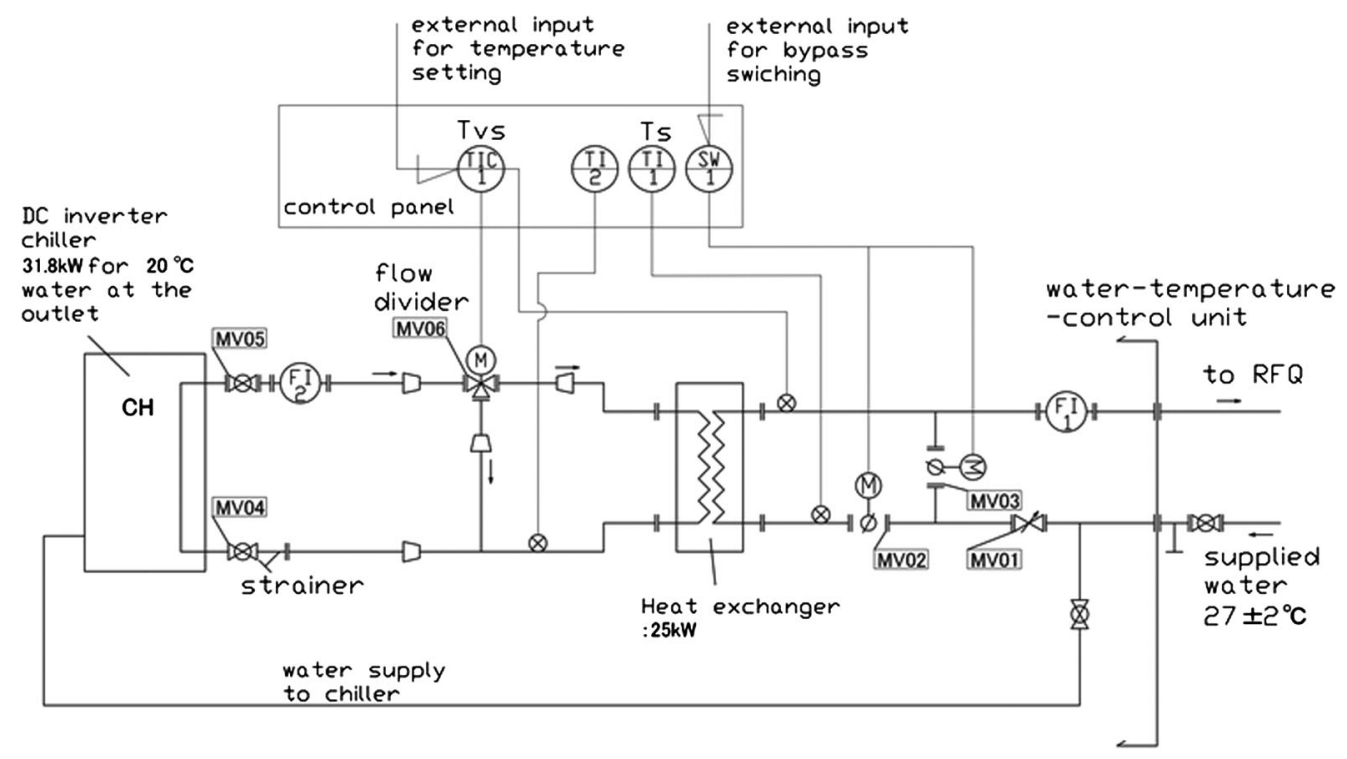

FIG. 3. Schematic of the water-temperature-control unit for RFQ high-power test. 


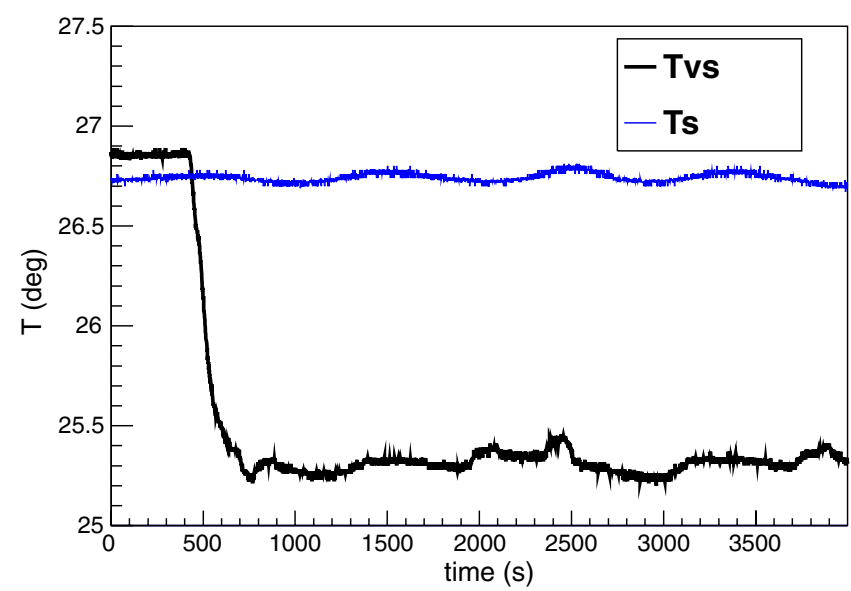

FIG. 5. Stability of water-temperature-control unit. Tvs is the temperature of the water provided to the vane channel, and $T \mathrm{~s}$ is that of the water supplied to this unit. At $t=430 \mathrm{~s}$, $T$ vs was changed from 26.9 to $25.3^{\circ} \mathrm{C}$, and after about $300 \mathrm{~s}, T$ vs became stable within $\pm 0.13^{\circ} \mathrm{C}$.

cooler-side (primary) water passage using a proportionalintegral-derivative control method. The temperature of the water supplied by the utility, $T \mathrm{~s}$, is measured and indicated by TI2. All the temperature sensors are PT100. The maximum suppliable flow rate of this unit is $100 \mathrm{~L} / \mathrm{min}$, but for the high-power test of RFQ II, this unit was used with a flow rate of $80 \mathrm{~L} / \mathrm{min}$; at this flow rate, the variable range of $T$ vs was $24-27^{\circ} \mathrm{C}$. The target temperature of $T$ vs can be set via the front panel of the unit and also by an external voltage input to the TIC1. The primary water is cooled by a DC inverter unit chiller (Daikin UWAXP8BPA5 [19]), and the temperature and flow rate are measured by FI2 and TI2, respectively. Additionally, the unit has valves, MV2 and MV3, to bypass this unit. These valves can also be remote controlled, providing an external signal to switch SW1.

Figure 5 shows the stability of this unit. In this figure, the target temperature of $T \mathrm{vs}$ was changed to $25.3^{\circ} \mathrm{C}$ at $t=$ $430 \mathrm{~s}$. After about $300 \mathrm{~s}$, Tvs became stable within $\pm 0.13^{\circ} \mathrm{C}$.

\section{CONDITIONING RESULTS}

In this section, the conditioning results for RFQ II are described. RFQ II was conditioned at a 324-MHz highpower test stand in the J-PARC linac building. Figure 6 is a photograph of RFQ II under high-power conditioning.

After all the components were assembled, the measured unloaded $Q$ value was 9436 . This corresponds to $87 \%$ of a SUPERFISH [20] calculation. The coupling factor of the $\mathrm{rf}$ coupler was set to 1.7. The vacuum pressure inside the cavity was measured with a BA gauge, and the rf power was turned off if the pressure exceeded $1.0 \times 10^{-4} \mathrm{~Pa}$.

Figure 7 shows the conditioning history of RFQ II. First, the pulse width and repetition rate were set to $30 \mu \mathrm{s}$ and $25 \mathrm{~Hz}$, respectively. After $15 \mathrm{~h}$ of conditioning, the peak

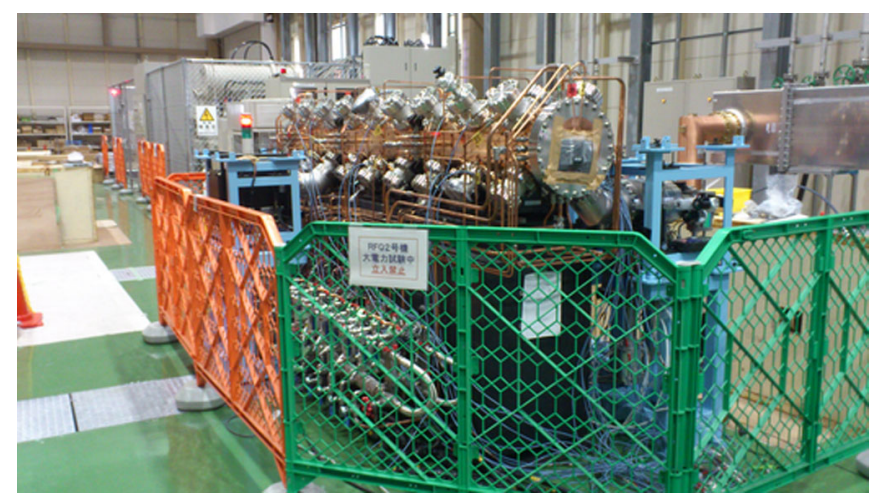

FIG. 6. Photograph of RFQ II under conditioning. This photograph shows the view from upstream, and the rf power is fed from the right side of the picture.

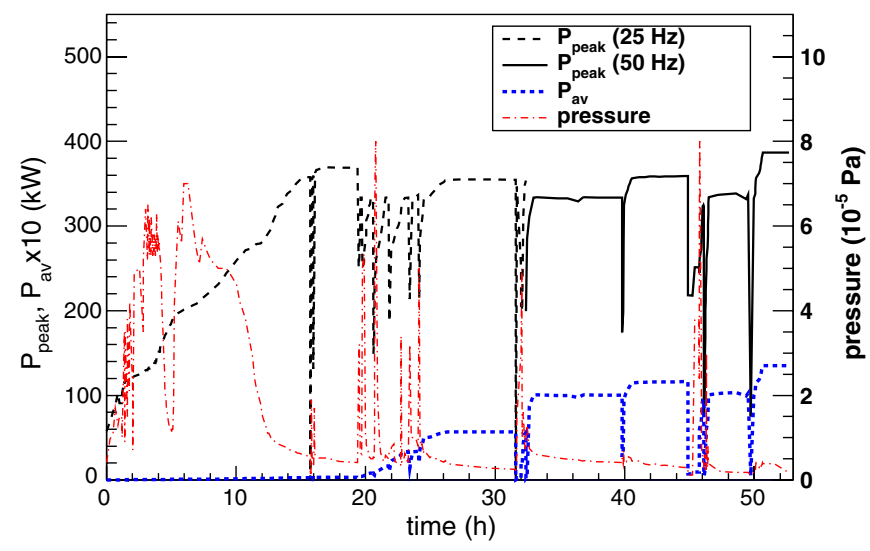

FIG. 7. Conditioning history of RFQ II.

power $P_{\text {peak }}$ reached $360 \mathrm{~kW}$; this is $10 \%$ higher than the nominal peak power of $330 \mathrm{~kW}$. The pulse width was gradually broadened to $600 \mu \mathrm{s}$, and then the repetition rate was increased to $50 \mathrm{~Hz}$. Finally, the conditioning was continued until $P_{\text {peak }}$ reached $390 \mathrm{~kW}$ with a pulse width of $600 \mu \mathrm{s}$ and a repetition rate of $50 \mathrm{~Hz}$. In Fig. 7, the dashed and solid (black) lines represent $P_{\text {peak }}$ at repetition rates of 25 and $50 \mathrm{~Hz}$, respectively. The dotted line (blue) is the averaged power $P_{\mathrm{av}}$, and the dash-dotted (red) line represents the vacuum pressure in the cavity. After conditioning up to $390 \mathrm{~kW}$, a $24-\mathrm{h}$ operation test was conducted at the nominal power. During the 24-h operation, trips occurred only 3 times, and it was confirmed that RFQ II can be operated stably.

\section{MODELING}

In designing RFQ II, two-dimensional finite-element method (FEM) analyses were performed [21] to estimate the frequency tuning range by changing the water temperature. It is easy to make a model for a two-dimensional simulation, and calculation is fast; however, it is a simple model that omits detailed cavity structures such as the fixed 
tuners and end part of the cavity. Therefore, it is essential to verify the model by comparing it with experimental data. In this section, the simulation method is reviewed briefly, and the parameter tuning of the model for comparison with the experimental results is described.

The temperature distribution and deformation due to heat loading of the RFQ were analyzed using ABAQUS [22]. First, the distribution of the heat load on the cavity surface was calculated using SUPERFISH, and this was input to ABAQUS. Subsequently, the steady-state temperature distribution in the cavity cross section was derived, as shown in Fig. 8. Using this distribution, the deformations of each segment, $d x$ and $d y$, from the initial state, which is a uniform $27^{\circ} \mathrm{C}$, were calculated with ABAQUS. Finally, using the above $d x$ and $d y$, the frequency shift $\Delta f$ was calculated from the $d f / d x$ and $d f / d y$ values of each segment obtained with SUPERFISH.

The heat convection factor $h$ and power dissipation to the model were tuned to reproduce the measured values of the temperature rises $\Delta T$ listed in Table II; they were measured at $P_{\text {peak }}=330 \mathrm{~kW}$ and a duty of $3 \%$. $T \mathrm{v} 1, T \mathrm{v} 2, \ldots$ are the water temperatures at the exits of the vane channels $\mathrm{V} 1, \mathrm{~V} 2, \ldots$, and $T \mathrm{w} 11, T \mathrm{w} 12, \ldots$ are those of the wall channels W11, W12, and so on. Moreover, $T \mathrm{v}_{a v}$ and $T \mathrm{w}_{a v}$ are the averaged temperatures at the exits of the vane and wall channels, respectively. At that time, the flow rates were $20 \mathrm{~L} / \mathrm{min}$ for the vane channels and $12 \mathrm{~L} / \mathrm{min}$ for the wall channels. Taking account of the temperature rises through the cooling-water channels, the averaged water temperature between the rfon and -off states were used for the cooling-water temperatures in the simulation $T \mathrm{v}_{\text {sim }}$ and $T \mathrm{w}_{\text {sim }}$; that is, both $T \mathrm{v}_{\text {sim }}$ and $T \mathrm{w}_{\text {sim }}$ were $27.2^{\circ} \mathrm{C}$. The derivation scheme for $T \mathrm{v}_{\text {sim }}$ and $T \mathrm{w}_{\text {sim }}$ is described in the next section. The temperature rises of each cooling water per unit length

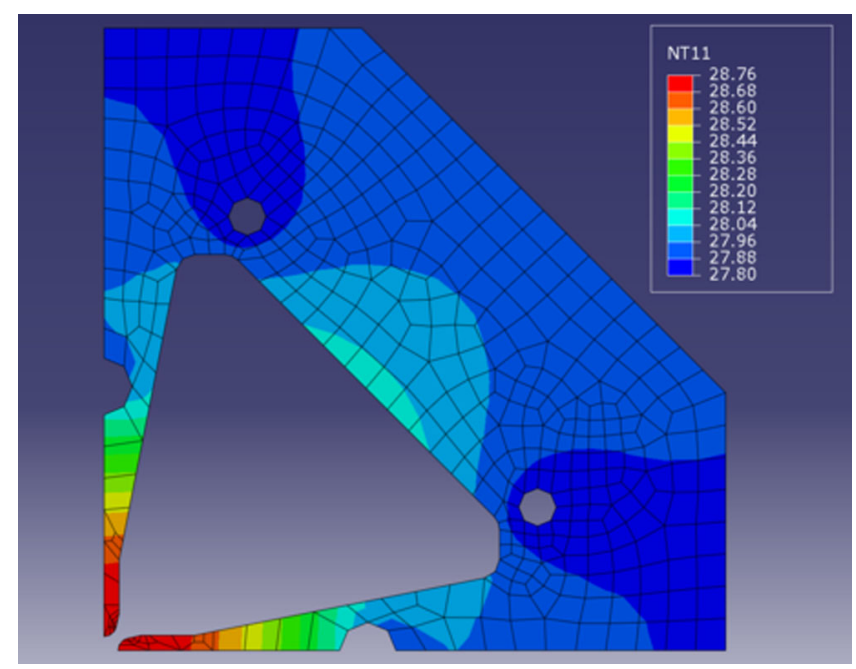

FIG. 8. Temperature distribution calculated with ABAQUS. The water temperatures of both the vane and wall channels are $27.2^{\circ} \mathrm{C}$. NT11 denotes the temperature at each node.
TABLE II. Measured temperature rise of each cooling-water channel with $P_{\text {peak }}=330 \mathrm{~kW}$ and a duty of $3 \%$. rf-off and rf-on indicate the temperatures at the exit of each channel when $\mathrm{rf}$ power is fed and not fed, respectively. $\Delta T$ denotes the difference between rf-on and rf-off.

\begin{tabular}{lccc}
\hline \hline & rf-off $\left({ }^{\circ} \mathrm{C}\right)$ & rf-on $\left({ }^{\circ} \mathrm{C}\right)$ & $\Delta T\left({ }^{\circ} \mathrm{C}\right)$ \\
\hline$T \mathrm{v} 1$ & 26.87 & 27.50 & 0.64 \\
$T \mathrm{v} 2$ & 26.96 & 27.58 & 0.63 \\
$T \mathrm{v} 3$ & 26.86 & 27.48 & 0.62 \\
$T \mathrm{v} 4$ & 26.93 & 27.51 & 0.58 \\
$T \mathrm{v}_{a v}$ & 26.90 & 27.52 & 0.62 \\
$T \mathrm{w} 11$ & 26.90 & 27.49 & 0.59 \\
$T \mathrm{w} 12$ & 26.88 & 27.51 & 0.62 \\
$T \mathrm{w} 21$ & 26.87 & 27.49 & 0.63 \\
$T \mathrm{w} 22$ & 26.85 & 27.46 & 0.61 \\
$T \mathrm{w} 31$ & 26.99 & 27.57 & 0.58 \\
$T \mathrm{w} 32$ & 26.88 & 27.47 & 0.60 \\
$T \mathrm{w} 41$ & 26.87 & 27.45 & 0.58 \\
$T \mathrm{w} 42$ & 26.86 & 27.46 & 0.61 \\
$T \mathrm{w}_{a v}$ & 26.89 & 27.49 & 0.60 \\
\hline \hline
\end{tabular}

can be derived from the power dissipation to each channel, which depends on $h$. The $h$ values were tuned to reproduce the measured values $\Delta T \mathrm{v}_{a v}$ and $\Delta T \mathrm{w}_{a v}$ normalized by the vane length. The obtained $h$ values are $7800 \mathrm{~W} / \mathrm{m}^{2} \mathrm{~K}$ for the vane channel and $8200 \mathrm{~W} / \mathrm{m}^{2} \mathrm{~K}$ for the wall channels. In this case, the calculated frequency shift from the rf-off state is $34 \mathrm{kHz}$, and the experimental result was $30 \mathrm{kHz}$.

\section{EXPERIMENTAL RESULTS}

In this section, the experimental results for verifying the model calculation described in the previous section are presented.

Figure 9 shows the frequency shifts from the rf-off state as a function of vane-water temperature. The closed circles represent the measured data, and the open squares are the simulation results. The horizontal axis represents the vanewater temperature. For the experimental data, the vanewater temperature is the averaged value of $T \mathrm{vs}$ and $T \mathrm{v}_{a v}$, and this value was used for the simulation as $T \mathrm{v}_{\text {sim }}$. The supplied water temperature for the cavity wall $T$ ws was not varied; however, the temperature rises of the wall channels also change if $T \mathrm{vs}$ is varied because the heat dissipation to the wall channel depends on the vane-water temperature. Therefore, the averaged value between the measured values $T$ ws and $T \mathrm{w}_{a v}$ was used as the wall-water temperature for the simulation, $T \mathrm{w}_{\text {sim }}$. The frequency responses to the change in the vane-water temperature obtained by linear fitting are $34 \mathrm{kHz} /{ }^{\circ} \mathrm{C}$ for the experiment and $32 \mathrm{kHz} /{ }^{\circ} \mathrm{C}$ for the simulation. The slope of the frequency shift to the vane-water temperature is reproduced well.

Next, the transient behavior when the status is changed from rf-on to rf-off is indicated in Fig. 10. The closed circles are the measured values, and the open squares are 


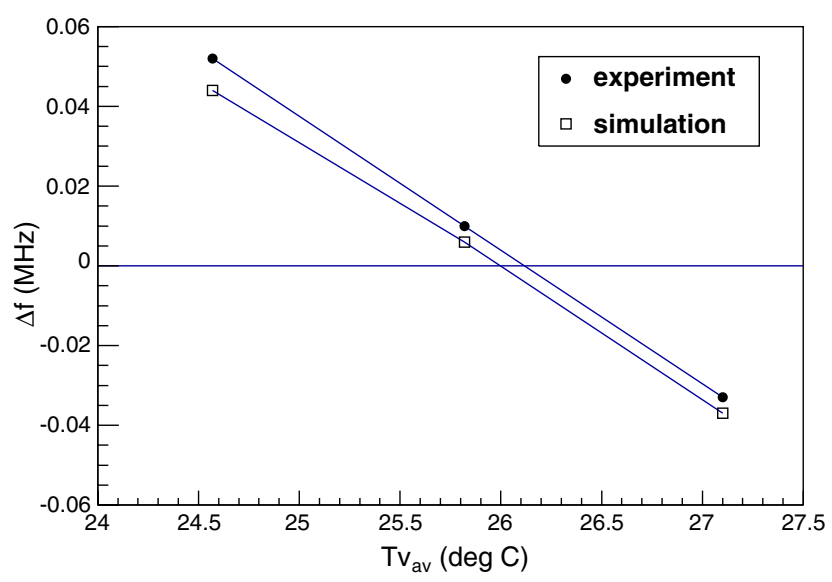

FIG. 9. Frequency response as a function of temperature of vane water. The vertical axis indicates the frequency shift from the rf-off state.

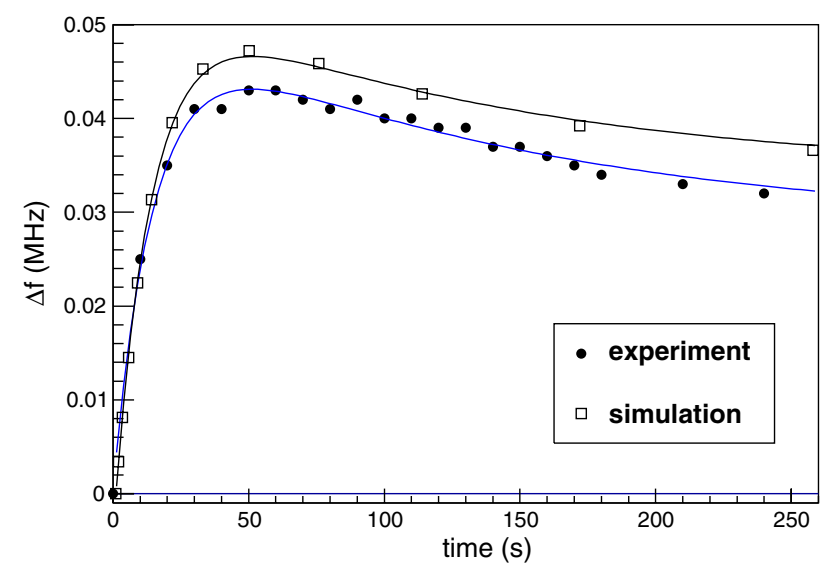

FIG. 10. Transient behavior after the rf power is turned off. The rf power was turned off at $t=0$. The vertical axis is the frequency shift from $t=0$.

the simulation. The horizontal axis represents the time after $\mathrm{rf}$ is turned off. The vertical axis denotes the frequency shift from $t=0$. At that time, $T \mathrm{v}_{a v}$ was $26.29^{\circ} \mathrm{C}$ and $T \mathrm{w}_{a v}$ was $27.06^{\circ} \mathrm{C}$. Both the measured and simulation data are fitted with

$$
\Delta f=c_{1}+c_{2} \exp \left(\frac{t}{\tau_{1}}\right)+c_{3} \exp \left(\frac{t}{\tau_{2}}\right) .
$$

In Fig. 10, the solid lines are the fitting results, and the fitting parameters are listed in Table III. The time constants of the measurement and simulation agreed with each other within $8 \%$.

Finally, the uniformity of the electromagnetic field was confirmed. If the resonant frequency is tuned by changing the vane water, the heat dissipation to the vane water becomes larger with decreasing temperature; thus, the temperature difference between the inlet and outlet of the water channel becomes larger. With the present setup, $T$ vs can be decreased to $24^{\circ} \mathrm{C}$, and the temperature rise through
TABLE III. Fitting results for the transient experiment and simulation.

\begin{tabular}{lccccr}
\hline \hline & $c_{1}(\mathrm{MHz})$ & $c_{2}(\mathrm{MHz})$ & $\tau_{1}(\mathrm{~s})$ & $c_{3}(\mathrm{MHz})$ & $\tau_{2}(\mathrm{~s})$ \\
\hline Experiment & 0.028 & -0.052 & -15 & 0.024 & 140 \\
Simulation & 0.034 & -0.059 & -14 & 0.020 & -130 \\
\hline \hline
\end{tabular}

the entire vane length is $1.2^{\circ} \mathrm{C}$. This temperature rise corresponds to $40 \mathrm{kHz}$ according to the measured frequency response mentioned above. Supposing that the frequency shift is linear from the inlets to the outlets, the field distortion of the fundamental TE210 mode due to this frequency shift is estimated to be about $0.1 \%$, which is negligibly small, by the perturbation method [23]. However, due to imperfections in the machining and fabrication, the distortion may be larger than expected. Thus, we investigated the field difference from no rf loading to the rf-on state, and also to the state with decreased vanewater temperature.

Figure 11 shows the change ratios of the field measured by pickup monitors. The upper figure represents the ratio of the variation in the voltage $\Delta V / V$ from a pulse width of $30 \mu \mathrm{s}$ and repetition rate of $50 \mathrm{~Hz}$ (duty $0.15 \%$ ) to those of $600 \mu \mathrm{s}$ and $50 \mathrm{~Hz}$, keeping both $T \mathrm{vs}$ and $T$ ws at $27^{\circ} \mathrm{C}$. The initial duty state, $0.15 \%$, simulates the no-rf-loading state. The field uniformity measured with the bead-pull method
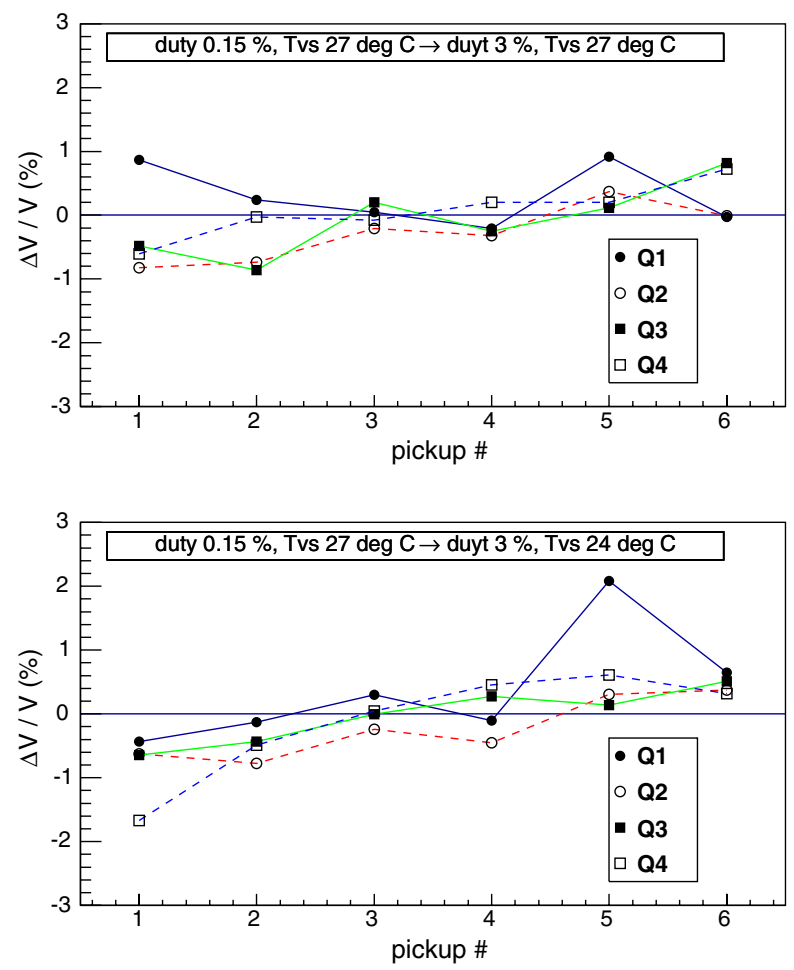

FIG. 11. Field distributions measured by pickup monitors. The upper figure represents the voltage difference $\Delta V / V$ between a duty factor of $0.15 \%$ and $3 \%$ keeping $T \mathrm{vs}=27^{\circ} \mathrm{C}$. The lower figure is $\Delta V / V$ from $T \mathrm{vs}=27^{\circ} \mathrm{C}$ and duty $=0.15 \%$ to $T \mathrm{vs}=$ $24^{\circ} \mathrm{C}$ and duty $=3 \%$. 
TABLE IV. PARMTEQM simulation results for field tilt. Here, $\varepsilon_{t}$ is the normalized rms transverse emittance, and $\varepsilon_{l}$ is the longitudinal emittance.

\begin{tabular}{lccc}
\hline \hline Tilt (\%) & Transmission $(\%)$ & $\varepsilon_{t}(\pi \mathrm{mm} \mathrm{mrad})$ & $\varepsilon_{l}(\pi \mathrm{MeV} \mathrm{deg})$ \\
\hline 0 & 97.7 & 0.18 & 0.84 \\
2 & 97.5 & 0.18 & 0.84 \\
\hline \hline
\end{tabular}

was within $\pm 1.5 \%$. In the lower figure, $\Delta V / V$ of $T \mathrm{vs}=$ $24^{\circ} \mathrm{C}$ from the initial low duty state is shown. From this figure, the field appears slightly tilted from the initial state. Therefore, estimating on the highest side, the effect of a $2 \%$ tilt on the beam dynamics was simulated using PARMTEQM [24]; a $2 \%$ tilt means that the voltage on the entrance end is $2 \%$ below the average voltage and that on the exit end is $2 \%$ above the average. In this simulation, the peak current of the input beam was $36 \mathrm{~mA}$, the normalized rms transverse emittance was $0.17 \pi \mathrm{mm}$ mrad, the transverse distribution was a water-bag distribution, the input energy was $50 \mathrm{keV}$, and the phase distribution was uniform.

Table IV lists the simulation results. From this result, a $2 \%$ tilt has very little effect on the quality of the beam; thus, the measured field change from no rf loading is not a problem.

\section{CONCLUSION}

A high-power test of J-PARC RFQ II was successfully conducted. In designing and fabricating RFQ II, various improvements from the first J-PARC RFQ (RFQ I) were made to increase the resistance to discharging. After $50 \mathrm{~h}$ of conditioning, the peak power reached $390 \mathrm{~kW}$, which corresponds to $118 \%$ of the nominal power of $330 \mathrm{~kW}$, with a pulse width of $600 \mu \mathrm{s}$ and a repetition rate of $50 \mathrm{~Hz}$. Moreover, 24-h operation with the nominal peak power was very stable. The resonant-frequency response to the vane-water temperature was investigated and compared to a two-dimensional FEM model. The measured frequency response was $34 \mathrm{kHz} /{ }^{\circ} \mathrm{C}$, and the simulated response was $32 \mathrm{kHz} /{ }^{\circ} \mathrm{C}$. The transient behavior was also measured, and the time constants of the measurement and simulation agreed with each other within $8 \%$. These results confirm that this simple FEM model is valid for using the RFQ design to predict the frequency response. Additionally, the electromagnetic field distributions at low duty $(0.15 \%)$, nominal duty (3\%), and different vane-water temperature $\left(27^{\circ} \mathrm{C}\right.$ and $\left.24^{\circ} \mathrm{C}\right)$ were measured. The field differences from the low duty state were within $2 \%$; this has a very small effect on beam dynamics. The results above fully confirmed the soundness of J-PARC RFQ II as a highpower rf cavity.

\section{ACKNOWLEDGMENTS}

The authors express their appreciation to Toyama Co., Ltd. for the mechanical design and fabrication of RFQ II.
The authors also thank Taiyo Valve Mfg. Co., Ltd. for their contribution to the water-temperature control unit.

[1] H. Hotchi, in Proceedings of IPAC2011, San Sebastián, Spain (EPS-AG, Spain, 2011), pp. 6-10.

[2] T. Koseki, in Proceedings of IPAC2011, San Sebastián, Spain (Ref. [1]), pp. 2499-2501.

[3] K. Hasegawa, in Proceedings of the 2007 Particle Accelerator Conference, Albuquerque, New Mexico (IEEE, New York, 2007) , pp. 2619-2623.

[4] A. Ueno and Y. Kondo, in Proceedings of the 20th International Linac Conference, Monterey, CA, 2000 (SLAC, Menlo Park, CA, 2000), pp. 545-547.

[5] K. Hasegawa, T. Kobayashi, Y. Kondo, T. Morishita, H. Oguri, Y. Hori, C. Kubota, H. Matsumoto, F. Naito, and M. Yoshioka, in Proceedings of IPAC2010 (ICR, Kyoto, Japan, 2010), pp. 621-623.

[6] T. Morishita, Y. Kondo, K. Hasegawa, F. Naito, M. Yoshioka, H. Matsumoto, Y. Hori, H. Kawamata, Y. Saito, and H. Baba, in Proceedings of LINAC2010 (KEK, Tsukuba, Japan, 2010), pp. 521-523.

[7] After the fabrication of RFQ II, the development of another RFQ with a design current of $50 \mathrm{~mA}$ was begun. This RFQ is called RFQ III [8], and its purpose is to upgrade the beam current of the J-PARC linac to achieve the original design power of $1 \mathrm{MW}$ (at the neutron target).

[8] Y. Kondo, K. Hasegawa, T. Morishita, and R. A. Jameson, Phys. Rev. ST Accel. Beams 15, 080101 (2012).

[9] H. Matsumoto, M. Akemoto, H. Hayano, A. Miura, T. Naito, and S. Takeda, in Proceedings of PAC91 (APS Beam Physics, San Francisco, California, 1991), pp. 1008-1010.

[10] T. Morishita et al., in Proceedings of LINAC2010 (Ref. [6]), pp. 518-520.

[11] T. Morishita, Y. Kondo, H. Kazuo, K. Hiroshi, S. Takashi, and N. Fujio, in Proceedings of LINAC2012 (Tel-Aviv, Israel, 2012).

[12] A. Ueno and Y. Yamazaki, Nucl. Instrum. Methods Phys. Res., Sect. A 300, 15 (1991).

[13] L. M. Young, in Proceedings of LINAC1994 (KEK, Tsukuba, Japan, 1994), pp. 178-180.

[14] The separation between the TE210 and the nearest dipole modes was estimated to be adjusted from 3 to $5 \mathrm{MHz}$ with DSRs in simulation. However, in actual measurement, the separation was optimum, that is $5 \mathrm{MHz}$, when the DSRs were $0 \mathrm{~mm}$. Therefore, actual RFQ II is not equipped with DSRs.

[15] R. Floersch and G. Domer, in Proceedings of the 19th International Linear Accelerators Conference, Chicago, Illinois, 1998 (NTIS, Springfield, VA, 1998), pp. 992-994.

[16] S. Virostek and J. Staples, in Proceedings of the 20th International Linac Conference, Monterey, CA, 2000 (Ref. [4]), pp. 908-910.

[17] Hitach Cable Ltd. [http://www.hitachi-cable.com].

[18] Toshiba Electron Tubes and Devices Co. Ltd. [http:// www.toshiba-tetd.co.jp/eng/].

[19] Daikin Industries Ltd. [http://www.daikin.com]. 
[20] J. H. Billen and L. M. Young, Technical Report No. LAUR-96-1834, 1996.

[21] Y. Kondo et al., in Proceedings of IPAC2010 (Ref. [5]), pp. 780-782.

[22] Dassault Systèmes, "ABAQUS" [http://www.3ds.com/ products/simulia/portfolio/abaqus/].
[23] T.P. Wangler, $R F$ Linear Accelerators (Wiley-VCH, Weinheim, 2008), 2nd ed.

[24] K. R. Crandall, T. P. Wangler, L. M. Young, J. H. Billen, G. H. Neuschaefer, and D. L. Schrage, Los Alamos National Laboratory Technical Report No. LA-UR-961836, 1996. 